TITLE:

\title{
Korea Expo 2012 and Its Digital Gallery Work Focusing Asian Four Gods
}

$\operatorname{AUTHOR}(\mathrm{S})$ :

Tosa, Naoko; Park, Jong-Il; Nakatsu, Ryohei

\section{CITATION:}

Tosa, Naoko ... [et al]. Korea Expo 2012 and Its Digital Gallery Work Focusing Asian Four Gods. 2013 International Conference on Culture and Computing 2013: 46-50

\section{ISSUE DATE:}

2013

URL:

http://hdl.handle.net/2433/250224

\section{RIGHT:}

(c) 2013 IEEE. Personal use of this material is permitted. Permission from IEEE must be obtained for all other uses, in any current or future media, including reprinting/republishing this material for advertising or promotional purposes, creating new collective works, for resale or redistribution to servers or lists, or reuse of any copyrighted component of this work in other works.; この論文は出版社版でありません。引用の際には出版社版をご確認ご利用ください。; This is not the published version. Please cite only the published version. 


\section{Korea Expo 2012 and Its Digital Gellery Work Focusing Asian Four Gods}

\author{
Naoko Tosa \\ Academic Center for Computing and \\ Media Studies \\ Kyoto University \\ Kyoto, 606-8501 Japan \\ tosa@media.kyoto-u.ac.jp
}

\author{
Jong-Il Park \\ Mixed Reality Laboratory \\ Hanyang University \\ Seoul 133791, Korea \\ jipark@hanyang.ac.kr
}

\author{
Ryohei Nakatsu \\ Interactive and Digital Media \\ Institute \\ National University of Singapore \\ Singapore 119613 \\ elenr@nus.edu.sg
}

\begin{abstract}
Yeosu World Expo 2012, with the theme of "ocean and its future," was held for three months in Yeosu, South Korea from May 12 until 12 August 2012. We have created a video artwork called "Four God Flags" for the exhibition at the Yeosu Expo. The created artwork was exhibited at the exhibition venue called Expo Digital Gallery during the expo. This paper describes the overview of the Expo and how this artwork has been created under the collaboration between an artist, designers, and engineering researchers so that it would fit the basic concept of the Expo.
\end{abstract}

Keywords-Expo; Yeosu Expo; Expo Digital Gallery; ocean and its future; Asian four gods

\section{INTRODUCTION}

Yeosu World Expo 2013 was held in Yeosu, South Korea for three months from May 122012 until August 12, 2012 [1][2]. The main theme of the Expo was "Ocean and Its Future." Infrastructures such as highways and KTX have been expanded significantly to attract people to the Expo and the surrounding areas of Yeosu, a medium size city with 300,000 population. As a result the visitors who attended the Expo topped to 7.5 million. The Expo organization committee mentioned about the Expo that it satisfied the three major elements required for each Expo; the number of customers, the evaluation by experts, and the implementation of the basic concept. The Secretary-General of International Expo Organization Mechanism evaluated it saying "the Yeosu Expo succeeded in realizing the expression of excellent contests and cultural events which visualized the basic concept of ocean and its future." In this paper the overview of the Expo will be described. Also the Expo Digital Gallery with the LED ceiling screen of $250 \mathrm{~m} \times 25 \mathrm{~m}$ will be described in detail, where the video artwork visualizing the concept that "Asia is one" created by the authors was exhibited.

\section{BACKGROUND}

Big events such as art exhibitions, technical exhibitions, etc. are good chances to demonstrate the achievements obtained through collaborations among people with different background. The authors have been carrying out collaborations in the interdisciplinary area between art and technology. One of the authors, Naoko Tosa, is a well known media artist who has been active in introducing technologies into media art and interactive art she has created. On the other side other two coauthors, Jong-Il Park and Ryohei Nakatsu, are researchers in the area of communication engineering and have been eager to integrate contents and technologies.

They started their collaboration when they were colleagues at ATR (Advance Telecommunication Research Institute) [3] in Japan in mid 1990s. At present they still continue their activities in different countries, so to speak Japan and Singapore[4][5][6][7]. These counties basically have different cultures but at the same time share lots of cultures as Asian countries[8][9]. Therefore based on their collaboration it is expected their collaboration would create new artworks that could fill the gap of various cultures in Asia and would express something core in the Asian culture[10][11].

Based on such basic understanding they discussed the basic concept of a video artwork called "Four Gods Flags" that would express the birth, fight, integration, and future of various Asian cultures. Fortunately this concept was accepted by Yeosu Expo 2012 Committee. Through the creation process of about more than one year they have created the video artwork which was exhibited at the Expo during its open period.

This paper describes first briefly describes about Yeos Expo 2012 and its main street called Expo Digital Gallary . Then it describes the artwork created by the authors focusing the relationship between the artwork and Yeosu Expo, the concept of the artwork, and the creation process of the artwork.

\section{OVERVIEW OF YEOSU EXPO 2012}

\section{A. Yеоsu Expo 2012}

The Expo is one of the world's oldest and largest international events sponsored by BIE (Beaurou International des Expositions)[12]. There are two types of Expos. One is the International Registered Exhibition (World Expo) which takes place every five years and lasts for six months. The World Expo is characterized by the broad scope of the chosen theme, which must be of universal concern to all of humanity. On the other hand International Recognized Exhibition (International Expo) is held between two World Expos and its duration is three months. The theme of the International Expo must represent, as with the World Expo, a global concern but it must be more specialized in its scope. For both Expos participants 
include states, international organizations, civil society groups, corporations, and citizens.

Yeosu Expo is one of International Expos and was held at New Port area in Yeosu, Korea from 12 May 2012 until 12 August 2012 for three months. The site of $2,710,000 \mathrm{~m} 2$ consists of exhibition area of $250,000 \mathrm{~m} 2$ and auxiliary facilities. The site has the geographical edge that comes from being adjacent to the ocean, and thus, is ideal for realizing the Expo theme, "The Living Ocean and Coast." The site overlooks Hallyeosdo Marine National Park and Odong Island, and is surrounded by 317 islets, having the perfect natural conditions to make the Expo's theme to come alive. The whole view of Yeosu Expo is shown in Fig. 1.

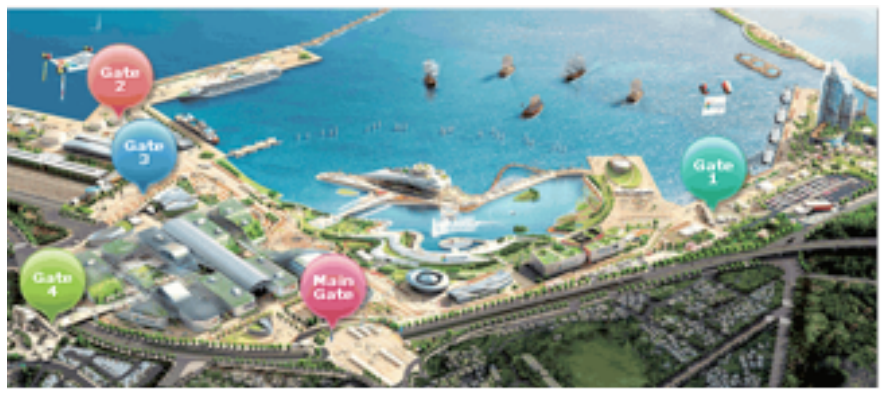

Fig. 1 Bird view of the Yeosu Expo site.

\section{B. Expo Digital Gallery}

Expo Digital Gallery (EDG) is one of the key architectures of the Expo. A large LED screen is installed on the ceiling on the passageway of the International Pavilion and is called EDG. The screen is 218 meters long and 30 meters wide which is 6,324 units of 60 inches TVs combined together. At the EDG several video works including our artwork were displayed.

Unlike other pavilions, it is not necessary for visitors to wait in a long line to watch the EDG, but they can simply look us and see the screen while walking and therefore EDG gathered a lot of attentions during the Expo. The view of EDG and international pavilions are shown in the left side of Fig. 2. Also the right side of Fig. 2 illustrates how EDG looks like.

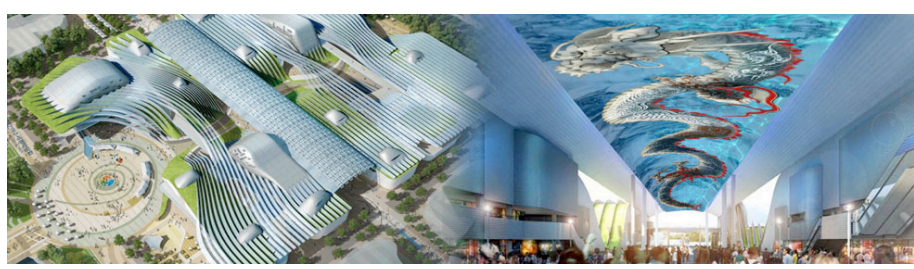

Fig. 2 Expo Digital Gallery and its inside.

\section{The process of the selection}

The construction company, GL, announced an open call for proposals the contents to be exhibited at EDG. Various persons and organization submitted their proposals and after their review our proposal on "Four Gods Flags" has been selected as one of video works to be exhibited at EDG during the Expo.

\section{CONCEPT OF Four GOD FlaGS}

From the ancient time both in Korea, China, and Japan, there has been a legend that four sacred beasts or four gods exist in four directions protecting people. These four gods are; the blue dragon of the east, the white tiger of the west, the red phoenix of the south, and the black turtle-snake of the south.

This idea has been related to the concept of "feng sui." Good fen sui is realized at a place with mountains in the back and water in the front, such as Yeosu city. It has been said that a place with good feng sui is well protected by the four gods.

In the Expo Digital Gallery, a main street of the 2012 Yeosu Expo, the images of these four gods will be shown in a huge ceiling LED display with the size of $218 \mathrm{~m} \times 30 \mathrm{~m}$ and appealing their dynamic movements to the audience.

The background images express underwater scenes with traditional Asian landscape taste. This is based on the idea of integrating traditional Asian culture and the ocean, that is the main theme of the Expo.

At the same time as Expo would be an occasion to show people the vision of our future world. We tried to express how knowledge and wisdom came out of old concept of the four gods and also tried to express our future where people all over the world could be united filling the gap of various cultures.

After the dynamic movements of the four gods, they are merged and is represented by the blue dragon, as 2012 is the year of dragon (Fig. 3 a, b, c, d).

Then the process of how human has progressed and obtained knowledge and wisdom throughout the long history is visualized by a group of old Chinese characters that came out of the blue dragon. These old Chinese characters gradually change into the normal Chinese characters and also change into a text (Fig. 3. e, f).

Then we tried to express the future when people would have richer wisdom, exchange their wisdom and share their wisdom filling the gap of countries and cultures through the image that each of these characters would change into a form of Maitreya and they chat each other. Maitreya is a god that appears in the long future and is relevant to express the image of out future. And then in the final stage the images of Maitreya change into the images of the four gods to express the dynamism human should maintain even in the future regardless of their country, culture and religion (Fig. 3. g, h). 
a

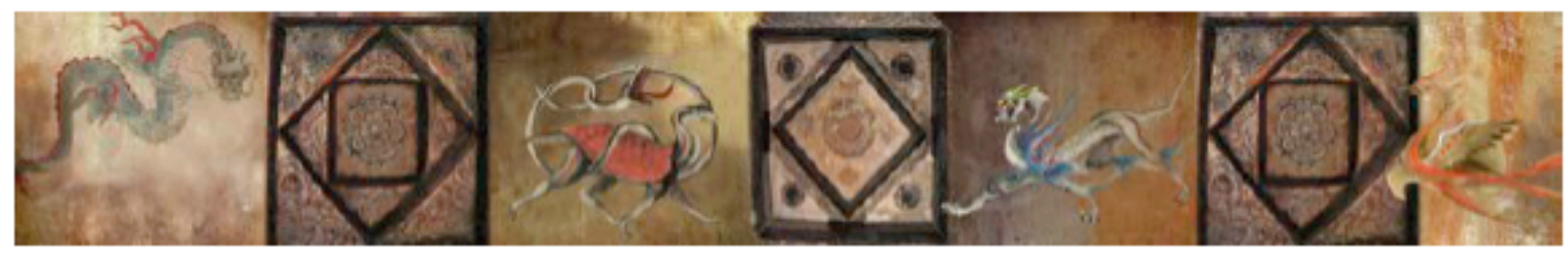

b

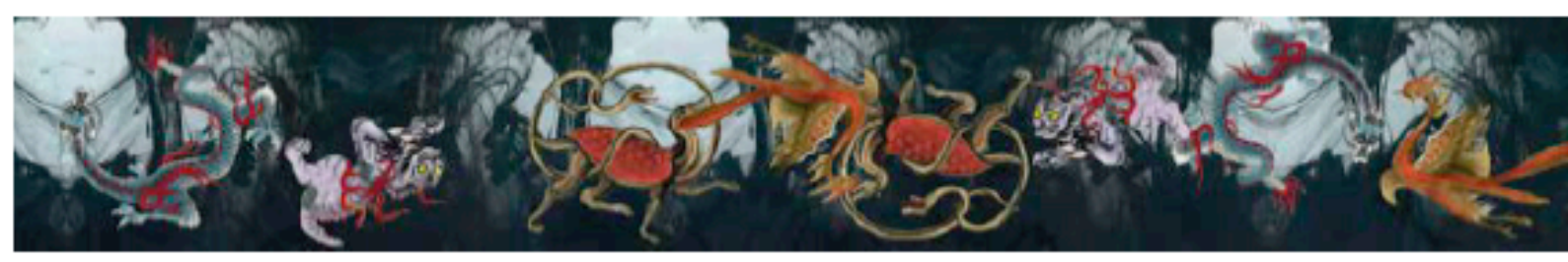

c

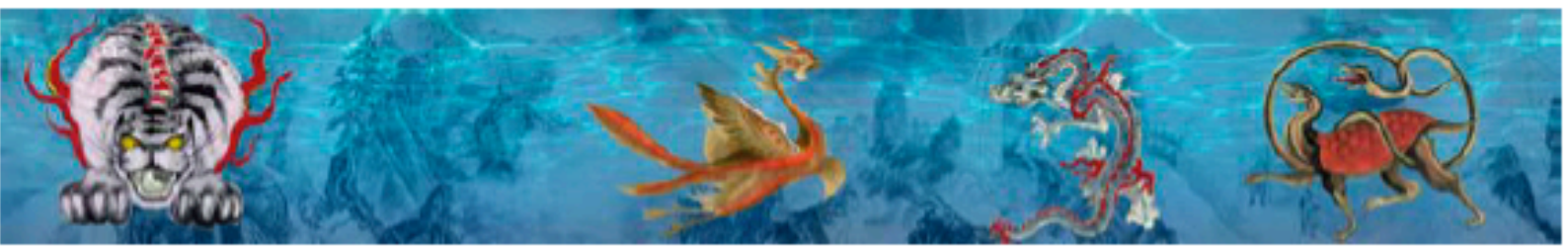

d

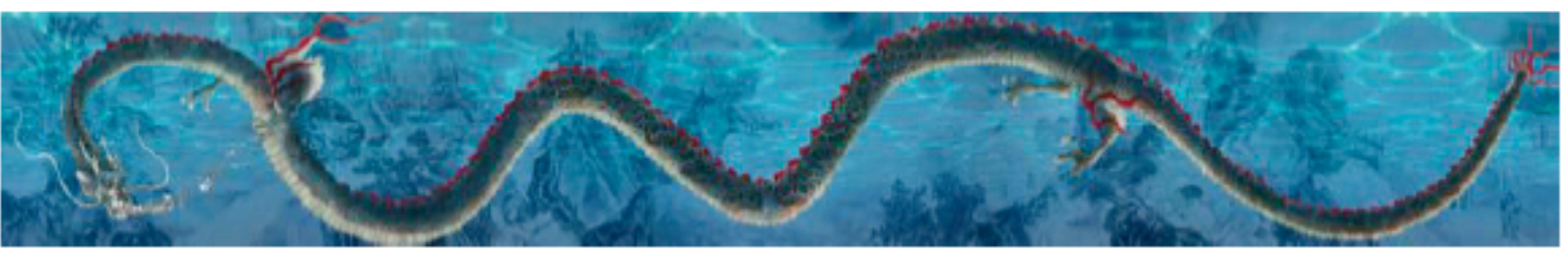

$\mathrm{e}$
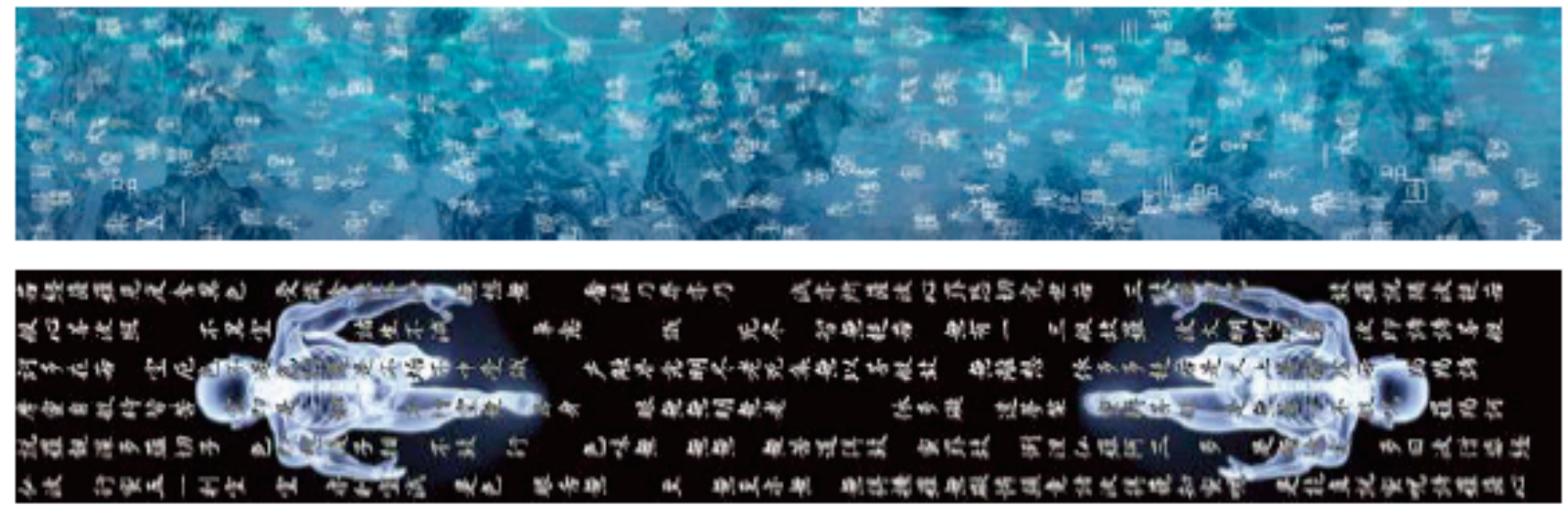

g

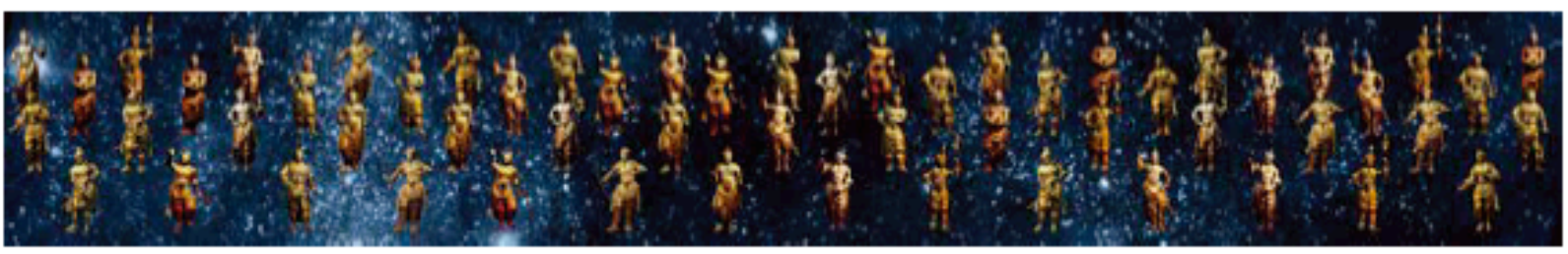

$\mathrm{h}$

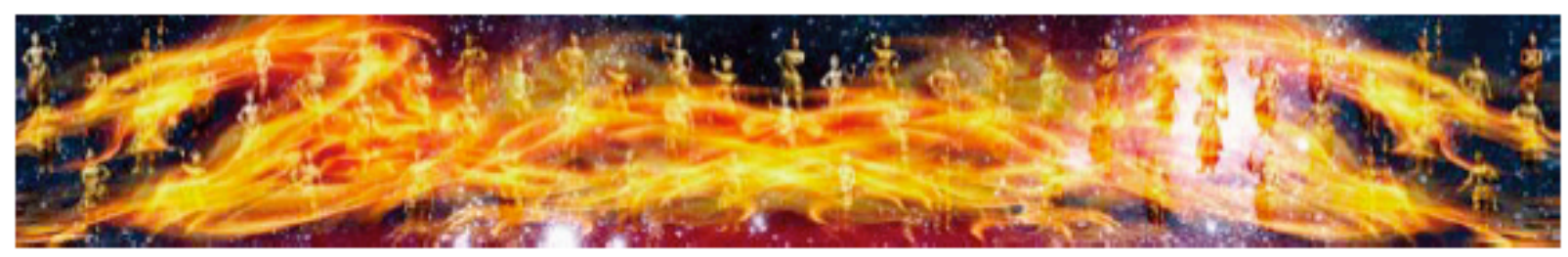

Fig. 3 Screen shot of the video artwork "Four God Flags" 


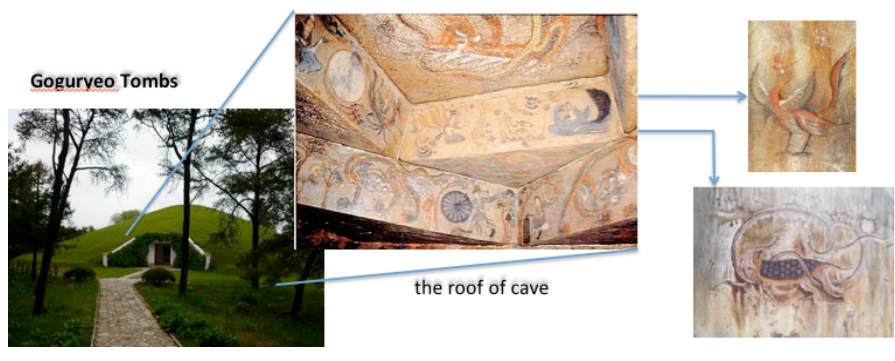

Fig. 4 Four God of Goguryeo Tombs

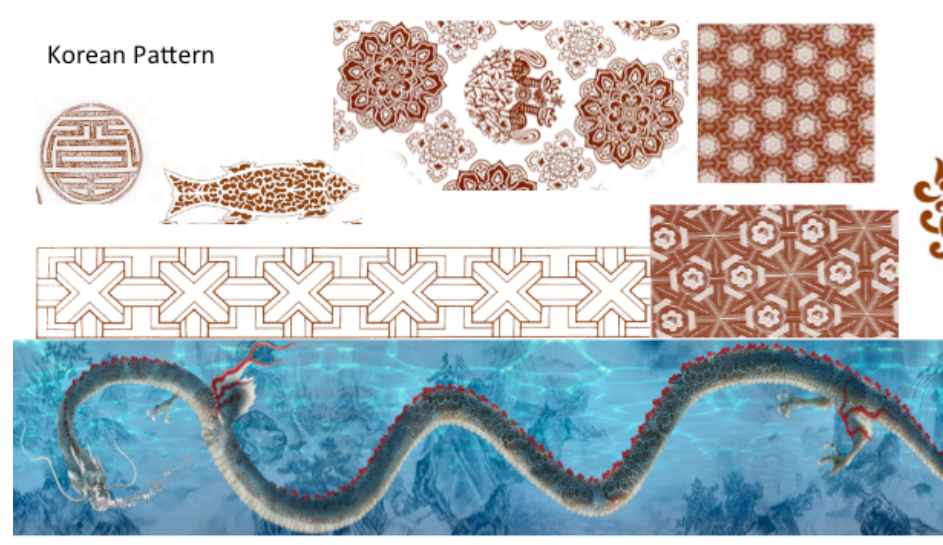

Fig.5 Dragon with Korean pattern

\section{CREation Process}

\section{A. Four Gods of Goguryeo Tombs and animation (Fig. 4)}

Four gods that are depicted on the ceiling of Goguryeo ancient tomb were used to express their resurrection. The video begins with a scene that these Gods begin to move slowly, directing the movement was solemn. The animation was created with hand-drawn images of all the keyframes, then with morphing animation assignment carried out on them.

\section{B. Dragon with Korean pattern}

Dragon is a sacred animal commonly used in Asian countries. we created the dragon image so that it looks like a dragon in Korea. It has big eyes, a feature of the Korean dragon, and its face is not thin like the Japanese dragon. As there are various beautiful patterns of dragon designs in South Korea, these patterns were attached to the body of the dragon it. It is very effective and you will see a very beautiful scene of dragon' swimming underwater. (Fig. 5.)

\section{Backgruond SANSUI image and oracle bone script animation}

As the theme of the Expo was "ocean," we have created a background landscape image expressing an ocean. The landscape image itself is an animetion which we created showing the old story of the Korean turtle that goes for a journey to get a rabbit heart for its king. In addition, the change from oracle bone scripts, which are the roots of Chinese characters, to modern Chinese characters is expressed by animation symbolizing the birth of wisdom. Then these characters change themselves into Heart Sutra symbolizing the Asian philosophy (Fig.6).
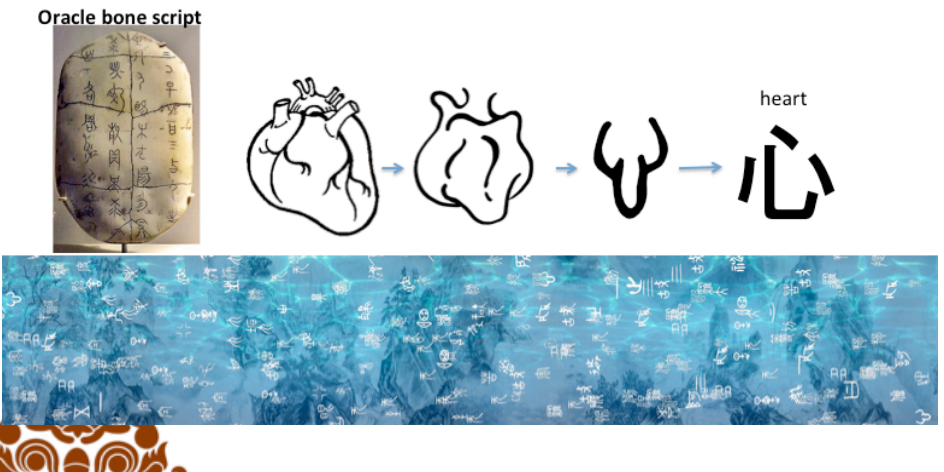

Ties 1 Ader water Sansui with Oracle bone script animation

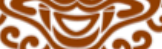

D. Projection on a big LED screen

Finally the created video artwork was displayed at Expo Digital Gallery (EDG) during the Expo. Within EDG there is alarge LED screen wich 218 meters long and 30 meters wide. Fig 7 illustrate how our video artwork looks like.

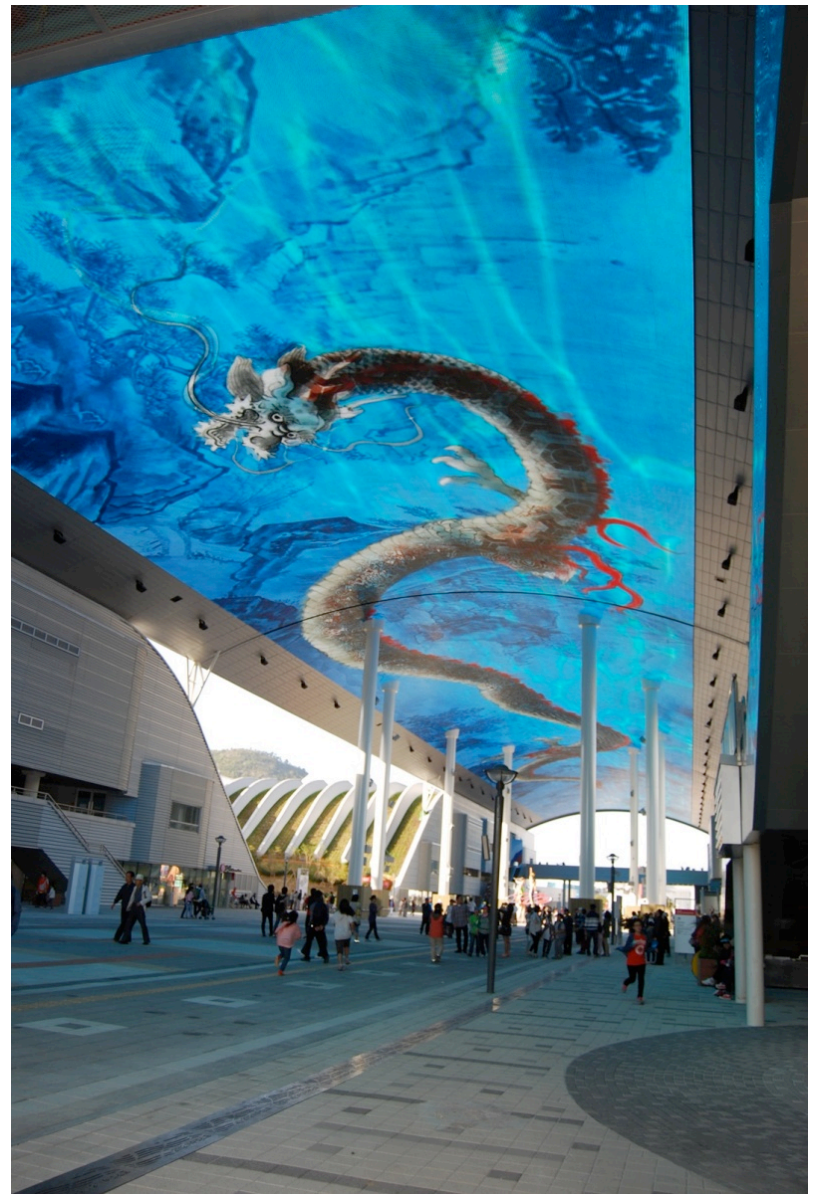

Fig.7 Four Gods Flags displayed on the EDG LED screen 


\section{CONCLUSION}

The created video artwork of "Four Gods Flags" was regularly exhibited with other video works the Expo Digital Gallery (EDG) of Yeosu Expo 2012 from mid May 2012 until mid August and gathered lots of attentions and interest from visitors of the Expo. Especially our artwork was recognized as the most distinguished one among the video works exhibited at EDG. Based on our contribution to the Expo, one of the authors of this paper, Naoko Tosa, was awarded by Yeosu Expo Committee (Fig. 8).

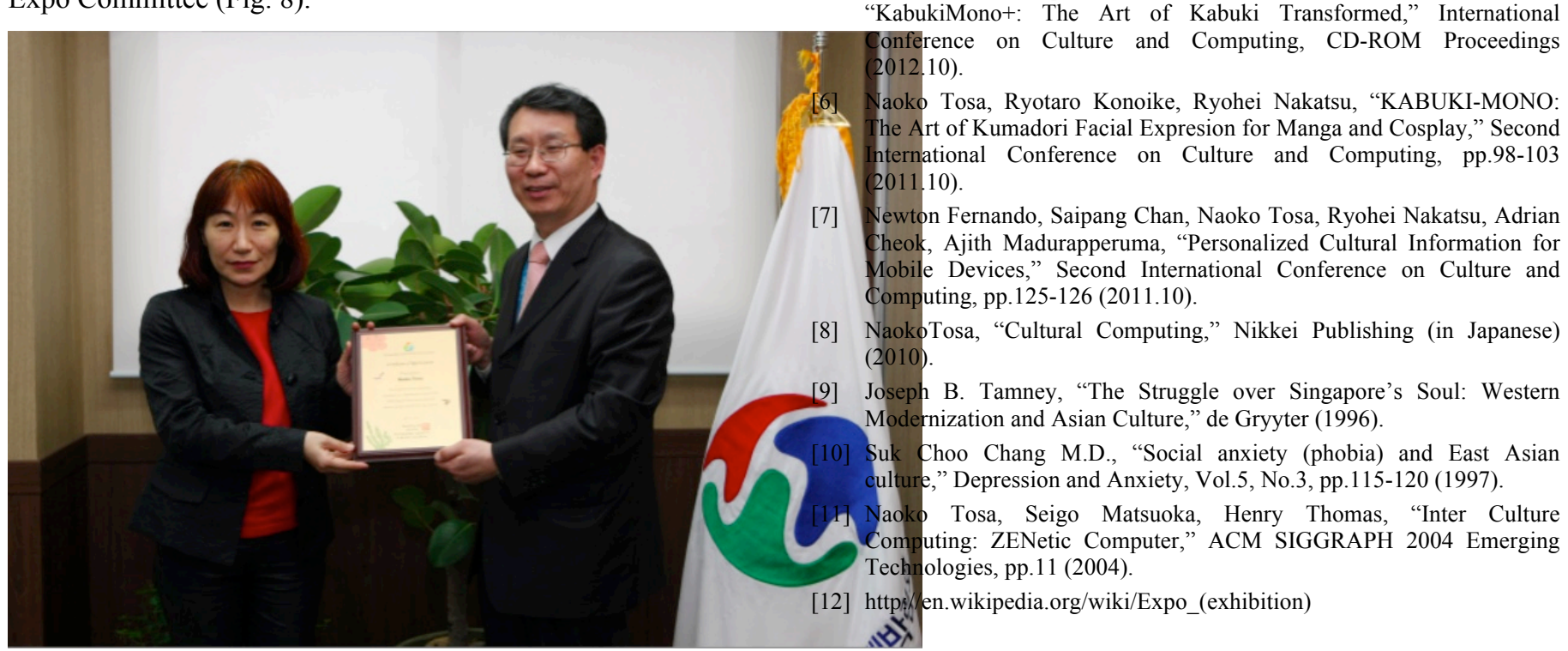

[1] http://www.worldexpo2012.com/

[2] http://jpn.expo2012.kr/main.html

[3] http://www.atr.co.jp/index_e.html

[4] Naoko Tosa, Jong-Il Park, Ryohei Nakatsu, "Digital Gallery Work 'Four God Flags' in Expo 2012 Korea and New Work of Silent-scape," 2012 International Academic Symposium, Invited Talk, pp.12-20 (2012.11)

[5] Naoko Tosa, Iroshan Horathalge, Kening Zhu, Kasthuri Jayarajah, Yohan Fernandopulle, Newton Fernando, Ryohei Nakatsu, onference on Culture and Computing, CD-ROM Proceedings Naoko Tosa, Ryotaro Konoike, Ryohei Nakatsu, "KABUKI-MONO: Newton Fernando, Saipang Chan, Naoko Tosa, Ryohei Nakatsu, Adrian Cheok, Ajith Madurapperuma, "Personalized Cultural Information for Mobile Devices," Second International Conference on Culture and

uk Choo Chang M.D. "Social anxiety (phobia) and East Asian ," Depression and Anxiety, Vol.5, No.3, pp.115-120 (1997)

Tosa, Seigo Matuoka, Heny Thomas, "Inter Culture

Fig. 8 Naoko Tosa receiving an award from Yeosu Expo Committee 